Bull. Chem. Soc. Ethiop. 2020, 34(3), 557-569.

ISSN 1011-3924

(c) 2020 Chemical Society of Ethiopia and The Authors

Printed in Ethiopia

DOI: https://dx.doi.org/10.4314/bcse.v34i3.11

\title{
STUDY OF THE HISTIDINE COMPLEX OF URANIUM(IV): SYNTHESIS, SPECTROPHOTOMETRIC, MAGNETIC AND ELECTROCHEMICAL PROPERTIES
}

\author{
Misbah Nazir ${ }^{1}$, Rozina Khattak ${ }^{2 *}$, Muhammad Sufaid $\mathrm{Khan}^{3}$ and Iftikhar Imam Naqvi ${ }^{1}$ \\ ${ }^{1}$ Department of Chemistry, University of Karachi, Karachi-75270, Pakistan \\ ${ }^{2}$ Department of Chemistry, Shaheed Benazir Bhutto Women University, Peshawar, Pakistan \\ ${ }^{3}$ Department of Chemistry, University of Malakand, Chakdara Dir (L), Pakistan
}

(Received June 20, 2020; Revised November 3, 2020; Accepted November 19, 2020)

\begin{abstract}
We synthesized the novel histidine complex of uranium(IV). A 1:3 mole ratio was found between metal and ligand by the mole ratio method, while $-\mathrm{NH}_{2}$ and $-\mathrm{COO}^{-}$groups of histidine behave as coordinating sites. The IR spectra confirmed the lone pair donating or coordinating sites. The elemental analysis confirmed the stoichiometry. The bathochromic shift with an increase in the optical density in the UV-Visible range indicated that the compound and its central metal ion hold uniform electronic charge distribution. The electrochemical results indicated a quasi-reversible (neither completely reversible nor completely irreversible) oxidation of the complex to its uranium(V) product at the platinum working electrode. The quasi-reversible process shows a comparatively slow electron transfer (ET) rate with the heterogeneous electron transfer rate constant ' $k s^{\prime}(3.4 \times$ $10^{-4} \mathrm{~cm} \mathrm{~s}^{-1}$ ) at $50 \mathrm{mV} \mathrm{s}^{-1}$ and $305 \pm 0.5 \mathrm{~K}$. The kinetics such as diffusion and charge transfer lead the reaction with an ECE (electrochemical-chemical-electrochemical) mechanism. The thermodynamic parameters of activation such as $\Delta \mathrm{H}^{*} ; 4.257 \mathrm{~kJ} \mathrm{~mol}^{-1}, \Delta \mathrm{S}^{*} ;-2.519 \times 10^{-3} \mathrm{~J} \mathrm{~mol}^{-1} \mathrm{~K}^{-1}$ and $\Delta \mathrm{G}^{*} 4.26 \mathrm{~kJ} \mathrm{~mol}^{-1}$ helped to propose an associative mechanism of the electron transfer at the platinum working electrode.
\end{abstract}

KEY WORDS: Uranium, Histidine, Spectroscopy, Electrochemistry, Kinetics

\section{INTRODUCTION}

Alpha-amino acid such as histidine has one carboxylic group and holds dibasic properties. If the " $\mathrm{R}$ " group of alpha-amino acid is replaced by the imidazole, we obtain histidine. The basicity of histidine comes from the imidazole group. Histidine carries four different groups that can contribute as bonding sites during complexation with the metal ion. These groups with bonding sites include the prime carboxyl and amino groups within the alpha amino acid. However, the two others are contributed by the imidazole compound such as secondary and tertiary nitrogen atoms [1-3]. In order to know the exact binding sites of the histidine, various studies appeared. Histidine coordinates with $\mathrm{Cu}(\mathrm{II})$ and $\mathrm{Mn}$ (II) by imidazole and amino sites, and, imidazole and the carbonyl sites, respectively $[4,5]$. Its coordination occurs by the tertiary nitrogen atom of imidazole group, and amino group if the metals are $\mathrm{Cu}(\mathrm{II}), \mathrm{Ni}(\mathrm{II})$ and $\mathrm{U}(\mathrm{VI})$ [6]. However, the study of the complexation of histidine with platinum metal ion shows the ionization and nonionization of the carboxyl group to form two complexes such as $\left[\mathrm{Pt}(\text { hist })_{2}\right]$ and $\left[\mathrm{Pt}(\text { hist }-\mathrm{H})_{2}\right]^{2+}$ [7]. The two nitrogen atoms yield the lone pair of electrons to form trans-planar geometry. The oxygen atom remains inactive towards coordination in the two complexes, which has ionized carboxyl group (IR band at 1625 and $1400 \mathrm{~cm}^{-1}$ ) and the non-ionized one (IR band at 1740 $\mathrm{cm}^{-1}$ ). The literature survey shows that the coordination of the histidine with any metal ion depends upon the experimental conditions and the nature of the metal ion. For example, it performs as a tridentate ligand during complexation with $\operatorname{Re}(\mathrm{V})$ and the ratio of ligand to metal appears 1:1 in the complex with the binding sites; $\mathrm{N}$ (amino group), $\mathrm{O}$ (carboxyl group) and $\mathrm{N}$ (imidazole compound). Meanwhile, the chemistry of histidine with rhenium, i.e. [ReO(L-Hist $\left.)_{2}\right]$

*Corresponding author. E-mail: rznkhattak@sbbwu.edu.pk; rznkhattak@yahoo.com

This work is licensed under the Creative Commons Attribution 4.0 International License 
shows the engagement of a tridentate ligand $(\mathrm{N}, \mathrm{N}, \mathrm{O})$ and a bidentate ligand $(\mathrm{N}, \mathrm{N})$ [8]. This chemistry appeared after mixing the 2:1 mole ratio of histidine with $\operatorname{ReOX}_{3}\left(\mathrm{OPPh}_{3}\right)\left(\mathrm{Me}_{2} \mathrm{~S}\right)$. The coordination of histidine by two nitrogen and one oxygen atoms have also been reported in the complex of technetium with histidine when the thioether is replaced by the histidine in $\left[\mathrm{Tc}(\mathrm{CO})_{3}\right.$ (thioether)] to yield $\left[\mathrm{Tc}(\mathrm{CO})_{3} \mathrm{Hist}\right]$ [9]. The electrochemical studies of the complexes of histidine with various metal ions have also been performed to know the correct stoichiometry. The synthesis of histidine complexes of cadmium $(\mathrm{Cd})$ and zinc $(\mathrm{Zn})$ was probed through polarography with the estimation of the log of formation constant such as 11.10 and 12.3 for $\left[\mathrm{Cd}(\mathrm{Hist})_{2}\right]$ and $\left[\mathrm{Zn}(\mathrm{Hist})_{2}\right]$, respectively [10]. Cobalt complex with histidine ligand was synthesized and physicochemically characterized by solubility testing, melting point, UVspectra and FTIR [11].

Investigation of the ligation of radiotoxic elements such as uranium with compounds present in living organisms and especially in mammals is key knowledge for the development of methods to counter the effects of radiation poisoning. A recent interest drew the attention when a series of uranium(IV) complexes with two different types of ligands such as hydrochalcogenido and chalcogenido were synthesized to surface the effect of variation in the binding sites upon the molecular and electronic structure of the complexes [12]. The complexation of uranium(IV) with Me-naphthaquinoline was studied and its reactivity as a multielectron reducing agent to release two electrons through the cleavage of the $\mathrm{C}-\mathrm{C}$ bond was reported [13]. Mixed ligand dioxouranium complexes with 8-hydroxyquinoline and some selected amino acids were synthesized [14]. Their molecular structures were determined and the antibacterial studies were performed. Uranium is undoubtedly toxic and its level of toxicity depends upon its chemistry in different compounds with its different oxidation states as well as the exposure pattern [15]. The most potent toxicants in animals were supposed to be uranyl $\left(\mathrm{U}^{\mathrm{VI}}\right)$ compounds which are relatively more water-soluble. Uranium in its +4 oxidation state has been reported to carry moderate-to-low systemic toxicity because of low solubility in water. However, the water-insoluble uranium compounds show less toxicity but could cause pulmonary toxicity if inhaled. The inhalation of uranium causes comparatively high toxicity than that of ingestion may because of the comparatively low gastrointestinal absorption of uranium compounds. Our interest was to synthesize the complex of uranium(IV) with histidine and to determine its stoichiometry, spectrophotometric, magnetic, electrochemical and thermodynamic properties.

\section{EXPERIMENTAL}

\section{Materials and methods}

The Analar grade materials were used throughout the experimental work, which were purchased either from Merck, BDH and or Sigma Aldrich. Distilled and deionized water was used to prepare the solutions.

The calculated amount of uranyl nitrate hexahydrate was dissolved in dilute $\mathrm{HCl}(0.2 \mathrm{M})$ to prepare the yellow colored stock solution of uranyl ion. Hydrogen gas was introduced into the resulting solution for an hour and platinized alumina was used as a catalyst [16]. After one hour, we obtained a leaf green colored solution of uranium(IV).

The complex of histidine with uranium(IV) was synthesized by adding its aqueous solution directly into the solution of uranium(IV) with constant stirring at a $\mathrm{pH}$ between 4.5-5.0. The resulting green precipitates were filtered and washed. The filtration was carried out through Whatmann 542 followed by washing with water (distilled and deionized) and subsequently with ethanol (absolute 99\%). The yield was dried in a silica gel desiccator and found to be $74 \%$ after drying. The elemental analyses showed following results for $\left[\mathrm{U}^{\mathrm{IV}}(\mathrm{His})_{3}\right] \mathrm{NO}_{3} \cdot 4 \mathrm{H}_{2} \mathrm{O}$. The average percent purity was found to be 92 . It is worthwhile to mention here that potassium dichromate 
was titrated against the solution of the synthesized uranium(IV)-histidine complex to determine the percentage of uranium(IV). The barium salt of diphenylamine sulphonic acid was used as an indicator [16]. The rest of the elements such as $\mathrm{CHN}$ were determined through usual method(s) by using $\mathrm{CHN}$ analyzer. [ $\left.\mathrm{U}^{\mathrm{IV}}(\mathrm{His})_{3}\right] \mathrm{NO}_{3} \cdot 4 \mathrm{H}_{2} \mathrm{O}\left(834.494 \mathrm{~g} \mathrm{~mol}^{-1}\right)=\%$ Found: $\mathrm{C}, 24.00 ; \mathrm{H}, 3.50$; N, 14.00; U, 29.00. \%Calculated: C, 25.88; H, 3.83; N, 16.78; U, 28.52.

\section{Instrumentation}

The elemental analysis of the complex was carried out through CHN (Carlo Erba) instrument. The spectrophotometric data were recorded in the UV-visible region by Shimadzu UV-160A double beam spectrophotometer. The IR spectra were recorded on the Prestige-21 FTIR spectrophotometer. The MS balance (magnetic susceptibility balance) was used to monitor the magnetic susceptibility of the synthesized complex in the solid state. The CHI 660C electrochemical workstation was used to study the electrochemical properties of the complex through cyclic voltammetry under nitrogen. A single three electrode cell consisted of a counter electrode (platinum wire), a working electrode (platinum), and a reference electrode $(\mathrm{Ag} / \mathrm{AgCl})$ helped to record the cyclic voltammograms between $0-1.5 \mathrm{~V}$ of the potential window from 298 $\mathrm{K}$ to $323 \mathrm{~K}$ temperature at different scan rates.

\section{RESULTS AND DISCUSSION}

\section{Spectrophotometric measurements}

The spectrophotometric measurements were carried out in the UV-visible region (Figure 1) at $\mathrm{pH}$ 5.0. The spectrum of the solution of uranium(IV) was recorded in the absence of histidine. The solution of histidine was mixed to the solution of metal ion in a different volume ratio. The colour was changed from leafy green to greyish-green. This arrangement helped to keep the concentration of the solution of metal ion constant and the ligand varied, and the spectral changes were recorded. After complexation, the absorption tendency of the metal ion increased. We observed an increase in the absorbance upon coordination of the histidine with uranium(IV), which becomes constant at $33.3 \mathrm{mM}$ and no further increase was observed upon increasing the concentration of histidine in the solution. Total five different absorption maxima $(\lambda)$ were observed in the spectra (Figure 1). The molar absorptivity $(\varepsilon)$ and energy of the metal ion, as well as the complex, were deduced at each of them in order to refine the results. The common formulation such as Beer-Lambert's law $(\mathrm{A}=\varepsilon \mathrm{bc})$ and Planck-Einstein relation $(\mathrm{E}=\mathrm{hc} / \mathrm{\lambda})$ were used to estimate the values of molar absorptivity and energy via considering the constant concentration of metal ion and complex ion $(0.01 \mathrm{M})$, where metal ion was the limiting reactant. Absorbance was divided by $0.01 \mathrm{M}$ in order to calculate molar absorptivity in both cases, i.e. metal ion and complex ion. The path-length of the cuvette was constant $(1 \mathrm{~cm})$. The energy was calculated by multiplying $4.136 \times 10^{-15} \mathrm{eV} \mathrm{s}\left(h\right.$; Planck's constant) to $3 \times 10^{17} \mathrm{~nm} \mathrm{~s}^{-1}$ (c; the velocity of light) and dividing by the particular wavelength $(\lambda)$. The data show an almost equal bathochromic shift at 644.0 and $631.0 \mathrm{~nm}$, the increase in absorbance was, however, higher at $644.0 \mathrm{~nm}$ rather than $631.0 \mathrm{~nm}$. This helped to conclude the uniform electronic charge distribution over the central metal ion and its whole compound, and shows that the largest decrease in the transition energy occurs at the transitions between the ground level ${ }^{3} \mathrm{H}_{4}$ and ${ }^{1} \mathrm{G}_{4}$ [17-18]. A minor bathochromic shift at wavelengths $653 \mathrm{~nm}$ and $663 \mathrm{~nm}$ was observed. The data was used to determine the mole ratio between the metal ion and the ligand, which was found to be 1:3 (Scheme 1, Figure 2). 


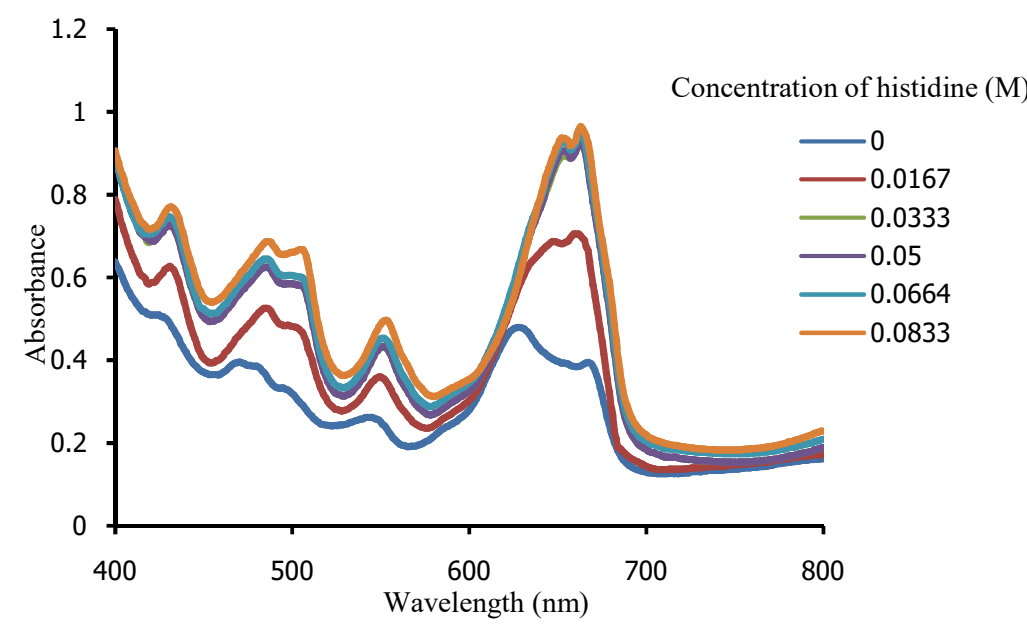

Figure 1. Spectral changes (UV-Vis region) at various concentrations of histidine by keeping uranium(IV) constant $(0.01 \mathrm{M})$.

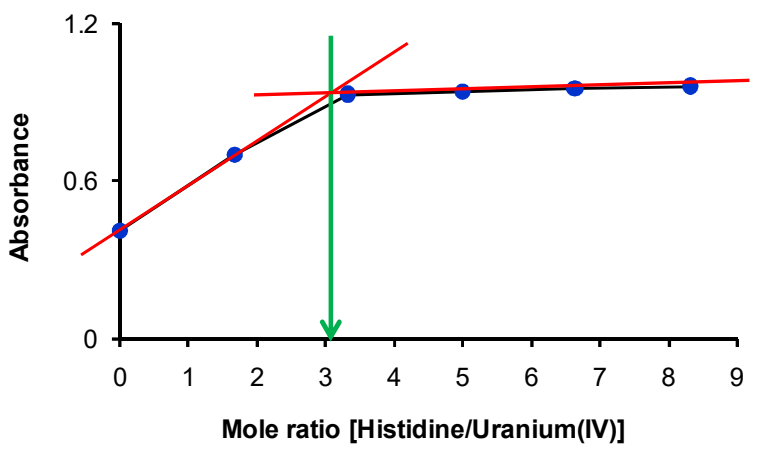

Figure 2. Mole ratio of uranium(IV)-histidine complex at $653 \mathrm{~nm}$.

Infrared spectroscopic analysis

The IR spectra of the histidine and the synthesized complex have been shown in Figure 3. We observed the representative $\mathrm{OH}$ (water molecule) and $\mathrm{NH}$ (primary amine) stretching vibrations in the spectrum of the complex at 3450 and $3130 \mathrm{~cm}^{-1}$. We have also observed the characteristic bands of the carboxyl group at 1620 and $1402 \mathrm{~cm}^{-1}$. The peak at $1496 \mathrm{~cm}^{-1}$ corresponds to the bending vibration of the $\mathrm{NH}_{2}$ group, which leads to the vibrations in the ring at $623 \mathrm{~cm}^{-1}$. However, the other two types of the vibrations such as twisting and wagging of the $\mathrm{NH}_{2}$ group appeared at 1100 and $1010 \mathrm{~cm}^{-1}$, respectively. The different modes of vibrations of the existing COO group in the complex gave rise to the peaks at 736, 659, and $561 \mathrm{~cm}^{-1}$, which may correspond to its wagging, bending and rocking. The peaks at around 530 and $441 \mathrm{~cm}^{-1}$ may lead to coordinating sites such as oxygen and nitrogen; $\mathrm{M}-\mathrm{O}$ and $\mathrm{M}-\mathrm{N}$, respectively [12, 1920]. The peak at high energy $\left(530 \mathrm{~cm}^{-1}\right)$ may correspond to $\mathrm{U}-\mathrm{O}$ coordination if we consider the 
electronegativity, availability of lone pair of electrons and opposite charges on uranium(IV) and oxygen ions that form strong bonding as compared to U-N. The peak at $441 \mathrm{~cm}^{-1}$ is though may due to the coordination of nitrogen atom with uranium(IV). The other peaks at 1589, 1480, 1380, and $909 \mathrm{~cm}^{-1}$ may represent $\mathrm{C}=\mathrm{N}$ and $\mathrm{C}=\mathrm{C}$ stretching, $\mathrm{CH}$ wagging, and $\mathrm{CH}$ rocking vibrations, respectively $[7,21]$. However, the peak at $1325 \mathrm{~cm}^{-1}$ represents $\mathrm{NO}_{3}{ }^{-}$counter ion [22].
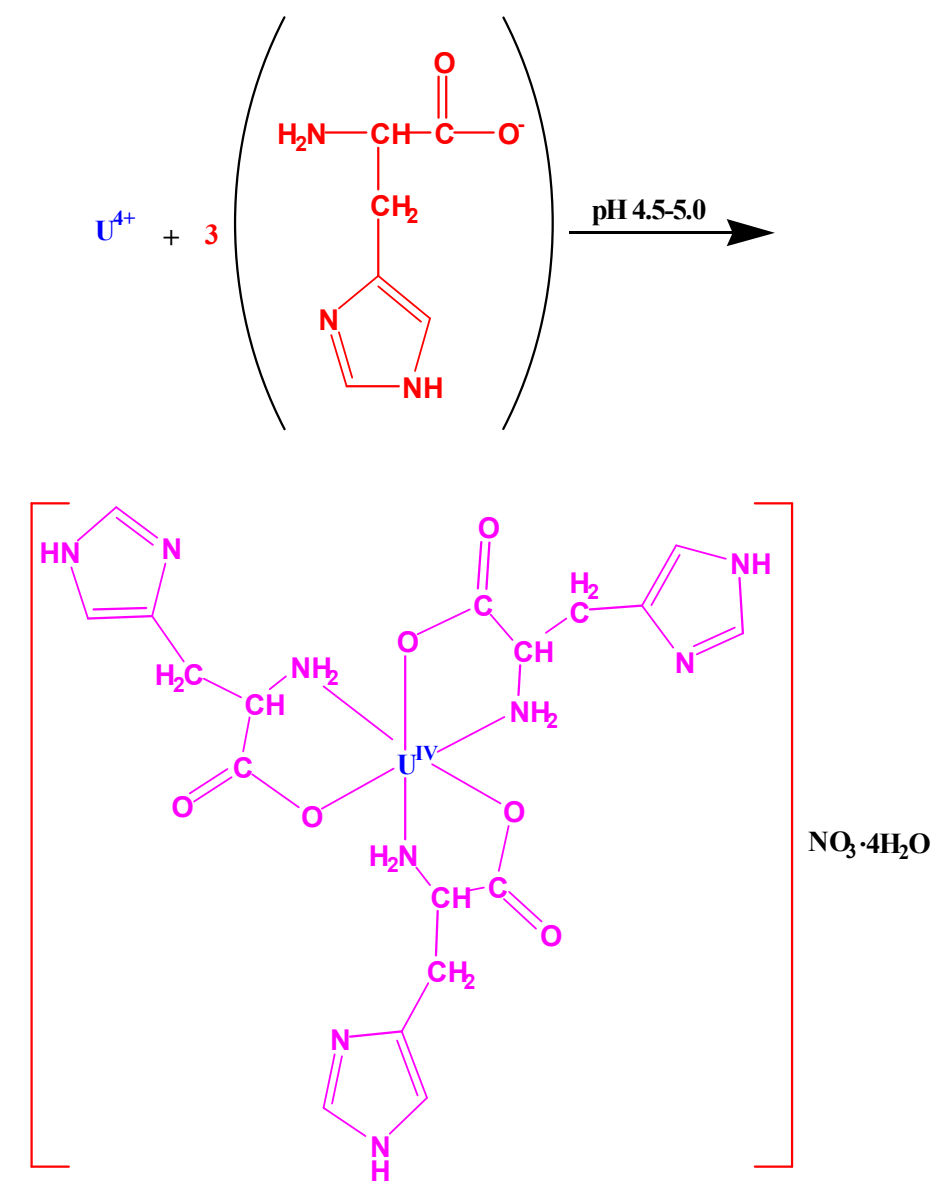

Scheme 1. Histidine complex of uranium(IV), $\left(\left[\mathrm{U}^{\mathrm{IV}}(\mathrm{His})_{3}\right] \mathrm{NO}_{3} \cdot 4 \mathrm{H}_{2} \mathrm{O}\right)$.

\section{Magnetic properties}

Table 1 describes the results carried out to determine the magnetic susceptibility of the synthesized complex of histidine with uranium(IV). Curie law was used to calculate these values. According to this law the magnetization of a paramagnetic complex is directly proportional to the applied magnetic field and inversely proportional to the temperature. It has been concluded that the magnetic moments $(\mu)$ are not isolated, while we compared the experimental results with the theoretically calculated values [23]. The results show that the number of unpaired electrons that leads to producing paramagnetic character in the complex appears to be two (2) that is consistent with the theoretical value. 


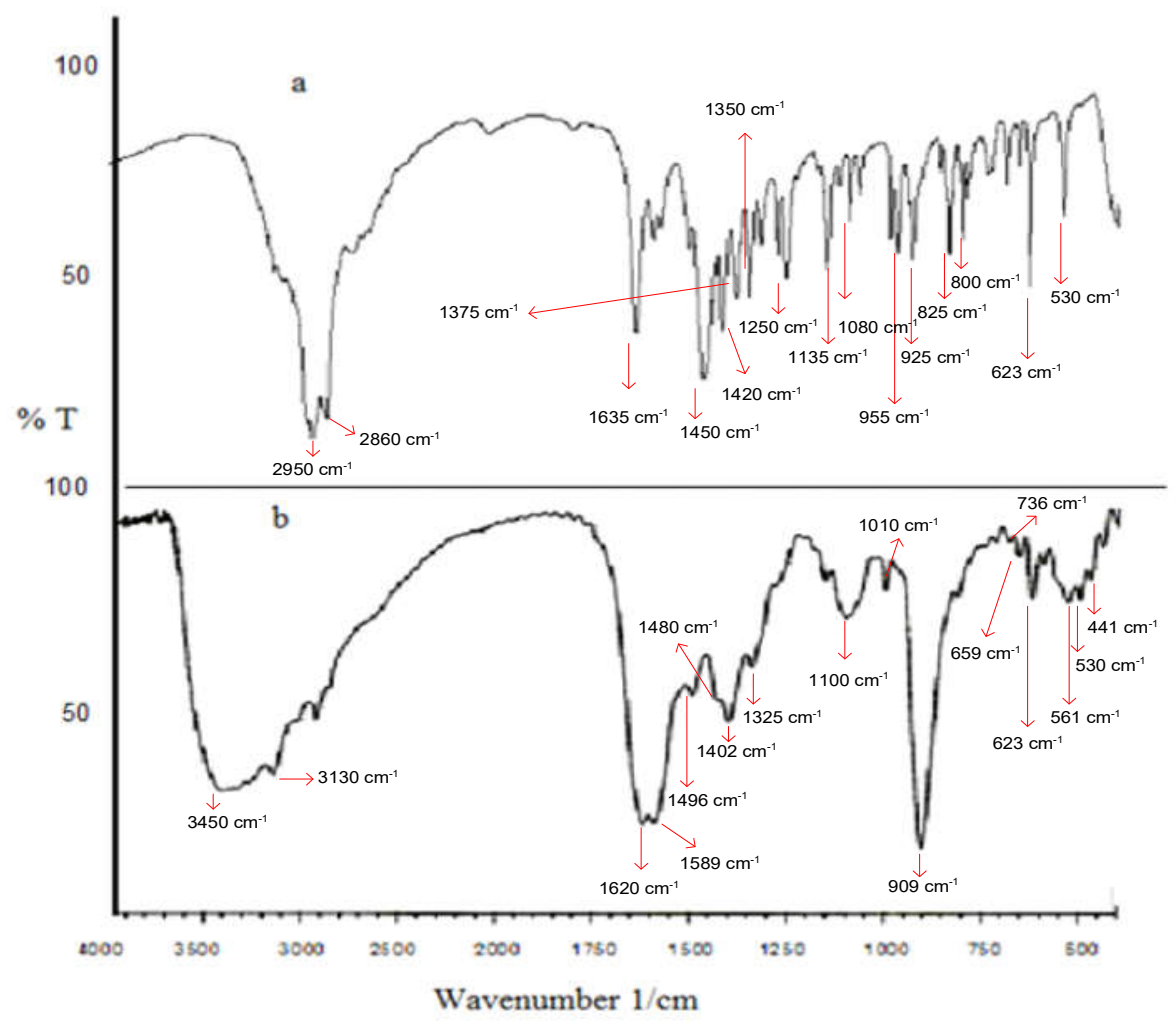

Figure 3. IR spectra (a) L-histidine and (b) uranium(IV)-histidine complex (KBr disc).

Table 1. Magnetic properties of the histidine complex of uranium(IV).

\begin{tabular}{|c|c|c|c|c|c|}
\hline $\mathrm{M}^{x} \mathrm{f}^{n}$ & $\mu_{\mathrm{so}}=[n(n+2)]^{1 / 2}$ & $\mu_{\mathrm{eff}}=\left(8 \lambda_{\mathrm{m}} T\right)^{1 / 2}$ & $\begin{array}{c}T \\
(\mathrm{~K})\end{array}$ & $\begin{array}{c}n \\
\text { (calculated) }\end{array}$ & $\begin{array}{c}n \\
\text { (theoretical) }\end{array}$ \\
\hline $\mathrm{U}^{4+} \mathrm{f}^{2}$ & 2.83 & 2.75 & 304 & 1.77 & 2 \\
\hline
\end{tabular}

$\mu_{\mathrm{so}}=$ magnetic moment (spin-only), ${ }^{\mathrm{f}} \mu_{\mathrm{eff}}=$ magnetic moment (experimentally effective/calculated) and $\mathrm{n}=$ unpaired electrons/uranium ion (this was calculated from $\mu_{\mathrm{eff}}$ using $\mu=[n(n+2)]^{1 / 2}$ ).

\section{Electrochemical properties}

The electrochemical properties of the synthesized complex were monitored in the aqueous medium at varying scan rates under a nitrogen atmosphere. The concentration of the complex was fixed at $3.62 \mathrm{mM}$ in a $2 \mathrm{M} \mathrm{HClO}_{4}$ and $\mathrm{NaClO}_{4}$ (as an electrolyte) solution. The results are displayed in Figure 4. The best results were observed at a scan rate of $50 \mathrm{mV} \mathrm{s}^{-1}$. At the higher scan rates the shifts of anodic and cathodic peaks retained constant. We observed both of the peaks such as anodic and cathodic at $1.242 \mathrm{~V}$ and $1.010 \mathrm{~V}$, respectively at a scan rate of $50 \mathrm{mV}$ $\mathrm{s}^{-1}$. The appearance of the two peaks confirms the oxidation of the metal ion; uranium(IV) under a reversible process. The effect of an increase in the scan rate was observed at the anodic and cathodic peaks. We observed a shift in the peaks upon increasing the scan rate in such a way that the anodic peak shows a shift towards positive figures and the cathodic peak towards the 
negative figures. We determined the difference between $E p_{\mathrm{A}}$ and $E \mathrm{p}_{\mathrm{C}}$ and found it larger than that of the theoretical value, i.e. $0.05 \mathrm{~V}$, which is a characteristic value of the one electronexchange reversible reaction. These outcomes confirm that the reaction follows the charge transfer kinetics. The plot of anodic peak current versus the square root of scan rate yielded a straight line (Figure 5) and provides evidence that at the platinum electrode, uranium(IV) oxidized to uranium(V) in a quasi-reversible process [24]. The results suggest that the electron transfer rate is moderate and the reaction is not completely reversible and or completely irreversible. Here, the term reversible corresponds to a fast electron transfer rate with stable reduced and oxidized species in the vicinity. However, the irreversible term means a slow electron transfer rate that yields very stable product (reduced species, for example). We also calculated the ratio of cathodic to anodic peak current $\left(\mathrm{Ip}_{\mathrm{C}} / \mathrm{Ip}_{\mathrm{A}}\right)$ and found it less than "1", and drew a graph between $\mathrm{Ip}_{\mathrm{A}} / v^{1 / 2}$ and scan rate (Figure 6). The graph shows the value of $\mathrm{Ip}_{\mathrm{A}} / v^{1 / 2}$ decreases with an increase in the scan rate, which suggests an ECE (electrochemical-chemicalelectrochemical) mechanism with probable disproportionation of the unstable product; uranium(V) back to the reactant; uranium(IV) and the new product; uranium(VI) in the reaction vessel (Equations 1-2). An ECE mechanism corresponds to an electron transfer (ET) process initially and then finally with a chemical reaction in the middle of the two ET processes. However, we did not observe any evidence such as current for the reduction of uranium(VI) [25].

$U(I V) \leftrightarrow U(V)+e^{-}$

$2 U(V) \rightarrow U(I V)+U(V I)$

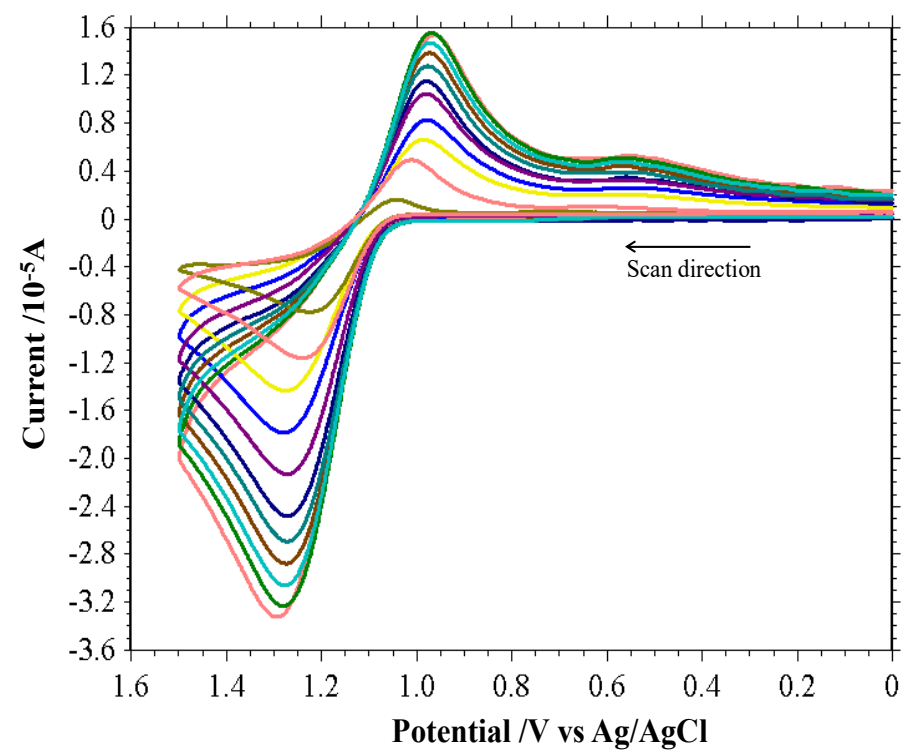

Figure 4. Cyclic voltammograms at $305 \pm 0.5 \mathrm{~K}$ and $20-500 \mathrm{mV} / \mathrm{s}$ scan rate in $2 \mathrm{M} \mathrm{HClO}_{4}$ and $\mathrm{NaClO}_{4}$ (electrolyte) at the platinum working electrode for the oxidation of uranium(IV)-histidine complex (3.62 mM). 


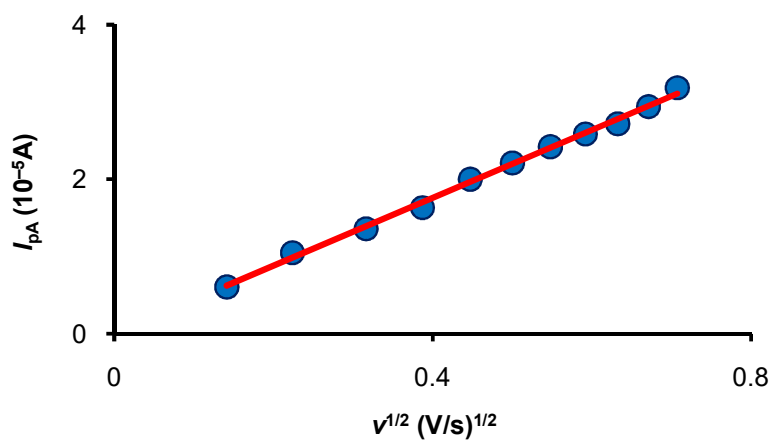

Figure 5. A plot of $\operatorname{Ip}_{\mathrm{A}}$ versus $v^{1 / 2}$.

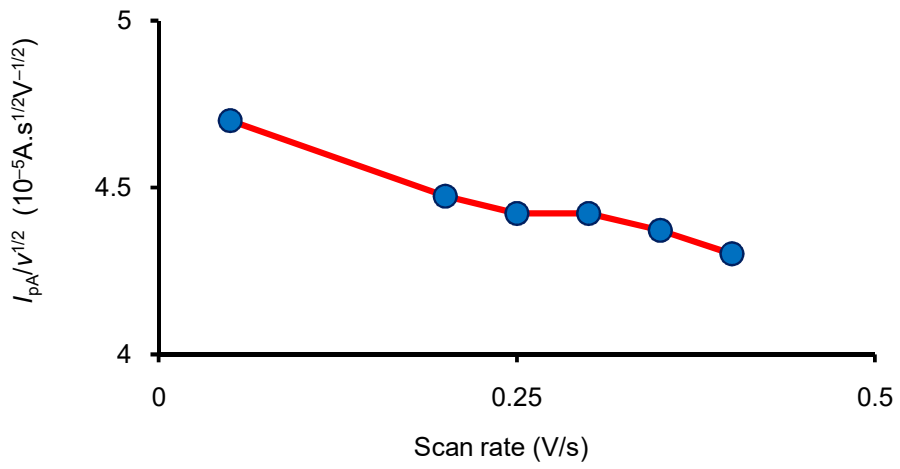

Figure 6. A plot of $\mathrm{Ip}_{\mathrm{A}} / v^{1 / 2}$ versus scan rate $(v)$.

\section{Electrochemical parameters}

We determined the electrochemical parameters such as the diffusion coefficient and the heterogeneous electron transfer rate constant by implementing equations 3-4. Equation 3 is commonly known as the Randles-Sevcik equation [26].

$I_{P}=0.4463(n F)^{3 / 2}(R T)^{-1 / 2} A C D_{o}^{1 / 2} v^{1 / 2}$

The symbols carry their conventional meanings and the universally established constant values such as; $I_{p}=$ peak current (amperes), $n=$ number of the electrons transferred during the redox process, $F=$ Faraday constant, $R=$ gas constant $\left(\mathrm{J} \mathrm{mol}^{-1} \mathrm{~K}^{-1}\right), T=$ temperature (Kelvin), $A=$ surface area of the electrode $\left(0.0314 \mathrm{~cm}^{2}\right.$, in our study), $C=$ concentration $\left(\mathrm{mol} / \mathrm{cm}^{3}\right), D_{o}=$ diffusion coefficient $\left(\mathrm{cm}^{2} / \mathrm{s}\right), v=$ scan rate $(\mathrm{V} / \mathrm{s})$.

A plot was drawn by keeping peak current on the y-axis and the square root of scan rate on the $\mathrm{x}$-axis in order to implement the equation (3). A linear correlation was observed between the peak current and the square root of the scan rate with a positive value of the slope $4.4 \times 10^{-5} \mathrm{~A}$ $\mathrm{V}^{-1 / 2} \mathrm{~s}^{1 / 2}$ (Figure 5). The value of the diffusion constant $\left(D_{o}\right)$ was calculated from the slope of the plot by inserting the constant values of various parameters, which helped to deduce it as $2.12 \times$ $10^{-6} \mathrm{~cm}^{2} \mathrm{~s}^{-1}$ [27].

Equation (4) helped to calculate the rate constant $\left(k_{s}\right)$ of heterogeneous electron transfer 
$k_{s}=2.18\left[\frac{\beta D_{o} n F v}{R T}\right]^{1 / 2} \exp \left[\frac{-\beta^{2} n F}{R T}\left(E_{p a}-E_{p c}\right)\right]$

The symbols $R, T, n, F, D_{o}$, and $v$ have the same meanings as in equation (3). However, $\mathrm{E}_{p a}$ and $\mathrm{E}_{p c}$ denote the anodic and cathodic peak potential, respectively. The value of $\beta$ is assumed to be 0.5 and is a dimensionless parameter, i.e. electron transfer coefficient. The heterogeneous electron transfer rate constant, $k_{s}$ was calculated and found to be $3.4 \times 10^{-4} \mathrm{~cm} \mathrm{~s}^{-1}$ by putting the values of $\beta$ and the constants along with the peak separation $\mathrm{E}_{p a}-\mathrm{E}_{p c}$ at a scan rate of $50 \mathrm{mV} \mathrm{s}^{-1}$ in equation (4) at $305 \pm 0.5 \mathrm{~K}$.

\section{Adsorption/desorption process at platinum electrode}

The adsorption and desorption processes during the electrochemical reactions are common, but it depends upon the nature of the reactant(s), product(s) and the working electrode involved. We probed this behavior of the novel complex at the platinum electrode. The cyclic voltammograms were collected for the same solution at a constant scan rate under nitrogen. A $3.62 \mathrm{mM}$ solution of the uranium(IV)-histidine complex was oxidized in $2 \mathrm{M}$ perchloric acid and sodium perchlorate at the scan rate of $50 \mathrm{mV} \mathrm{s}^{-1}$ and $305 \pm 0.5 \mathrm{~K}$. Sodium perchlorate $\left(\mathrm{NaClO}_{4}\right)$ was used as an electrolyte and the repetitive cyclic voltammograms (40 cycles) were recorded by using a platinum working electrode. The data neither show any change in the intensity of anodic/cathodic peak current nor the existence of post/pre-peak (Figure 7). This confirms the reactant and the product did not involve the adsorption/desorption process at the surface of the platinum electrode [28-29].

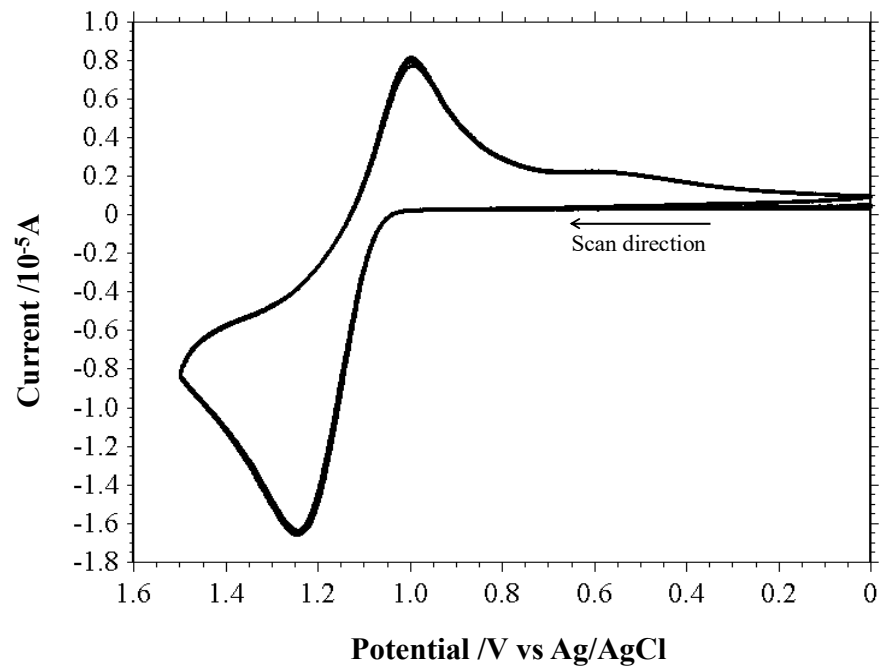

Figure 7. Repetitive cyclic voltammograms at $305 \pm 0.5 \mathrm{~K}$ and $50 \mathrm{mV} / \mathrm{s}$ scan rate in $2 \mathrm{M} \mathrm{HClO}_{4}$ and $\mathrm{NaClO}_{4}$ (electrolyte) at platinum working electrode for the oxidation of uranium(IV)-histidine complex (3.62 mM).

\section{Thermodynamic parameters of activation}

The thermodynamic parameters of activation were estimated by determining the value of the rate constant $\left(k_{s}\right)$ at a range of temperature. The heterogeneous electron exchange reaction, i.e. the oxidation of the synthesized complex at the platinum electrode was observed to be an 
endothermic process, because the rate constant increased with increasing temperature. In order to draw a graph and to determine the values of the activation parameters, we started from equations (5-7) and rearranged them to equation (8).

$k_{s}=Z_{\text {het }} \exp \left[\frac{-\Delta G^{*}}{R T}\right]$

$\ln k_{s}=\ln Z_{h e t}-\frac{\Delta G^{*}}{R T}$

$\therefore \Delta G^{*}=\Delta H^{*}-T \Delta S^{*}$

$\because \ln \left(\frac{k_{s}}{Z_{\text {het }}}\right)=\frac{-\Delta H^{*}}{R T}+\frac{\Delta S^{*}}{R}$

where, $Z_{\text {het }}=$ collision number $=(R T / 2 \pi M)^{1 / 2}$. The symbol $M$ represents the molecular weight of the reactants. The other symbols such as $R, T$, and $\pi$ (3.14) have their conventional meanings and values.

$10^{3} 1 / \mathrm{T}\left(\mathrm{K}^{-1}\right)$

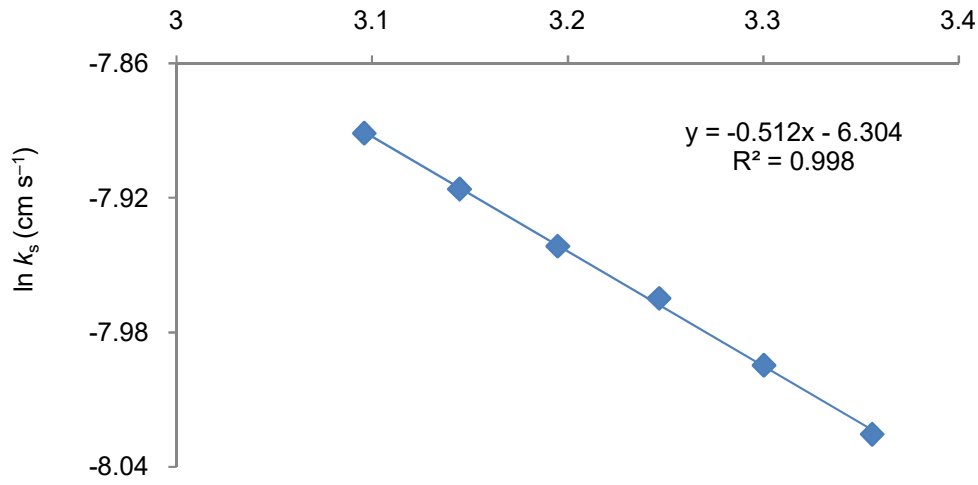

(a)

$10^{3} 1 / \mathrm{T}\left(\mathrm{K}^{-1}\right)$

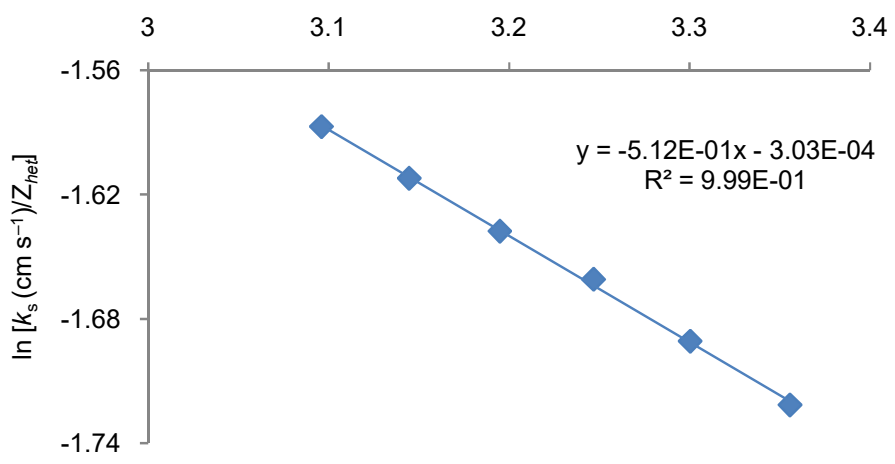

(b)

Figure $8(\mathrm{a}, \mathrm{b})$. Plots to determine the thermodynamic parameters of activation.

Bull. Chem. Soc. Ethiop. 2020, 34(3) 
The value $\left(4.26 \mathrm{~kJ} \mathrm{~mol}^{-1}\right)$ of the Gibbs free energy of activation $\left(\Delta \mathrm{G}^{*}\right)$ was determined by plotting $\ln k_{s}$ versus $1 / \mathrm{T}$ (Figure $8 \mathrm{a}$ ) according to equation (6). The intercept of the plot yielded the value of $Z_{\text {het }}$ as $1.829 \times 10^{-3}$. Equation (8) was implemented to estimate the values of the enthalpy $\left(\Delta \mathrm{H}^{*}\right)$ and entropy $\left(\Delta \mathrm{S}^{*}\right)$ of activation by drawing a plot between $\ln \left[k_{s} / Z_{\text {het }}\right]$ and $1 / \mathrm{T}$. A straight line obtained with a negative slope and an intercept, which helped to calculate the values of $\Delta \mathrm{H}^{*}\left(4.257 \mathrm{~kJ} \mathrm{~mol}^{-1}\right)$ and $\Delta \mathrm{S}^{*}\left(-2.519 \times 10^{-3} \mathrm{~J} \mathrm{~mol}^{-1} \mathrm{~K}^{-1}\right)$, respectively (Figure $8 \mathrm{~b}$ ). The positive value of the Gibbs free energy of activation shows the oxidation of the synthesized complex a non-spontaneous endothermic process at the platinum electrode [30-32].

\section{CONCLUSION}

Uranium(IV) if inhaled or ingested by animals through any source, it may form a stable water soluble complex with amino acid. Histidine coordinates with uranium(IV) by its oxygen anion of deprotonated carboxyl group and the nitrogen atom of $\mathrm{NH}_{2}$ group to yield an octahedral geometry. The complex absorbs maximum at the wavelengths 653 and $663 \mathrm{~nm}$ in the visible region. The metal to oxygen and metal to nitrogen coordination has been justified by our IR data and the previous studies $[12,19-20]$. The novel compound has paramagnetic nature with two unpaired electrons. The oxidation of the novel complex at the platinum working electrode is a quasi-reversible process with electrochemical-chemical-electrochemical mechanism. The low value of the heterogeneous electron transfer rate constant $3.4 \times 10^{-4} \mathrm{~cm} \mathrm{~s}^{-1}$ confirms the electron transfer under a quasi-reversible reaction with $2.12 \times 10^{-6} \mathrm{~cm}^{2} \mathrm{~s}^{-1}$ diffusion constant. The small positive values of the enthalpy and Gibbs free energy of activation and negative value of the entropy of activation indicated an associative mechanism at the platinum electrode. However, the results helped to conclude no adsorption and desorption at the platinum working electrode during the electrochemical oxidation of the complex, we synthesized in this study.

\section{ACKNOWLEDGEMENT}

The authors are grateful to the Higher Education Commission of Pakistan for funding this work under indigenous 500-PhD scholarship program.

\section{REFERENCES}

1. Garrett, R.H.; Grisham, C.M. Principles of Biochemistry with a Human Focus, Thomson Learning, Inc.: Online Publication; 2002; pp 70-71.

2. Devlin, T.M. Textbook of Biochemistry with Clinical Correlations, 3rd ed., Wiley-Liss: New York; 1992; pp 27-31.

3. Damodaran, S.; Parkin, K.L.; Fennema, O.R. Fennema's Food Chemistry, 4th ed., CRC Press: Boca Raton; 2007; pp 323-328.

4. Edsall, J.T.; Felsenfeld, G.; Goodman, D.S.; Gurd, F.R.N. The association of imidazole with the ions of zinc and cupric copper. J. Am. Chem. Soc. 1954, 76, 3054-3061.

5. Cohn, M.; Townsend, J. A study of manganous complexes by paramagnetic resonance absorption. Nature 1954, 173, 1090-1091.

6. Li, N.C.; Doody, B.E.; White, J.M. Some metal complexes of glycine peptides, histidine and related substances. J. Am. Chem. Soc. 1957, 79, 5859-5863.

7. Balice, V.; Theophanides, T. I.R. spectra of platinum(II) histidine complexes. J. Inorg. Nucl. Chem. 1970, 32, 1237-1240.

8. Tessier, C.; Rochon, F.D.; Beauchamp, A.L. Oxorhenium(V) complexes with the nonsulfur-containing amino acid histidine. Inorg. Chem. 2002, 41, 6527-6536. 
9. Seifert, S.; Künstler, J.-U.; Gupta, A.; Funke, H.; Reich, T.; Pietzsch, H.-J.; Alberto, R.; Johannsen, B. Reactivity of technetium(I) thioether carbonyl complexes towards histidine-an EXAFS study in solution. Inorg. Chim. Acta 2001, 322, 79-86.

10. Li, N.C.; Manning, R.A. Some metal complexes of sulfur-containing amino acids. J. Am. Chem. Soc. 1955, 77, 5225-5228.

11. Saha, S.; Dhanasekaran, D.; Chandraleka, S.; Panneerselvam, A. Synthesis, characterization and antimicrobial activity of cobalt metal complex against multi drug resistant bacterial and fungal pathogens. Facta universitatis-series: Phys. Chem. Tech. 2009, 7, 73-80.

12. Rosenzweig, M.W.; Hümmer, J.; Scheurer, A.; Lamsfus, C.A.; Heinemann, F.W.; Maron, L.; Mazzanti, M.; Meyer, K. A complete series of uranium(IV) complexes with terminal hydrochalcogenido $(\mathrm{EH})$ and chalcogenido (E) ligands $\mathrm{E}=\mathrm{O}, \mathrm{S}, \mathrm{Se}, \mathrm{Te}$. Dalton Trans. 2019, 48, 10853-10864.

13. Camp, C.; Andrez, J.; Pécaut, J.; Mazzanti, M. Synthesis of electron-rich uranium(IV) complexes supported by tridentate schiff base ligands and their multi-electron redox chemistry. Inorg. Chem. 2013, 52, 7078-7086.

14. Patil, S.S.; Thakur, G.A.; Shaikh, M.M. Synthesis, characterization, and antibacterial studies of mixed ligand dioxouranium complexes with 8-hydroxyquinoline and some amino acids. ISRN Pharmaceutics 2011, 2011, Article ID 168539. DOI: 10.5402/2011/168539.1-6.

15. Keith, S.; Faroon, O.; Roney, N.; Scinicariello, F.; Wilbur, S.; Ingerman, L.; Llados, F.; Plewak, D.; Wohlers, D.; Diamond, G. Health Effects in Toxicological Profile for Uranium, Agency for Toxic Substances and Disease Registry (US); 2013.

16. Naqvi, S.I.I. Protonation behaviour of 1:1 U(IV) EDTA complex, J. Chem. Soc. Pak. 1980, $2,35-36$.

17. Jorgensen, C.K. The nephelauxetic effect in uranium(IV) compounds. Chem. Phys. Lett. 1982, 87, 320-323.

18. Jeżowska-Trzebiatowska, B.; Bukietyńska, K. The electronic structure of uranium(IV) in complex compounds-I Comparison of the absorption spectra of uranium(IV) and praseodymium(III) compounds. J. Inorg. Nucl. Chem. 1961, 19, 38-42.

19. Andrews, L.; Wang, X.; Gong, Y.; Kushto, G.P.; Vlaisavljevich, B.; Gagliardi, L. Infrared spectra and electronic structure calculations for NN complexes with $\mathrm{U}, \mathrm{UN}$, and NUN in solid argon, neon, and nitrogen. J. Phy. Chem. A 2014, 118, 5289-5303.

20. Fielicke, A.; Gruene, P.; Haertelt, M.; Harding, D.J.; Meijer, G. Infrared spectroscopy and binding geometries of oxygen atoms bound to cationic tantalum clusters. J. Phy. Chem. A 2010, 114, 9755-9761.

21. Nakamoto, K. Infrared and Raman Spectra of Inorganic and Coordination Compounds, 3rd ed., Wiley Interscience Publication: USA; 1978; pp 305-312.

22. Goebbert, D.J.; Garand, E.; Wende, T.; Bergmann, R.; Meijer, G.; Asmis, K.R.; Neumark, D.M. Infrared spectroscopy of the microhydrated nitrate ions $\mathrm{NO}_{3}^{-}\left(\mathrm{H}_{2} \mathrm{O}\right)_{1-6}$. J. Phy. Chem. A 2009, 113, 7584-7592.

23. Magnetic Susceptibility Balance Instructional Manual, Magway England Ed.; 2001.

24. Giridhar, P.; Venkatesan, K.A.; Srinivasan, T.G.; Rao, P.R.V. Electrochemical behavior of uranium(VI) in 1-butyl-3-methylimidazolium chloride and thermal characterization of uranium oxide deposit. Electrochim. Acta 2007, 52, 3006-3012.

25. Hauchard, D.; Cassir, M.; Chivot, J.; Ephritikhine, M. Electrochemical study of uranium(IV) and uranium(IV) organometallic compounds in tetrahydrofuran by means of conventional microelectrodes and ultramicroelectrodes: Part I. Application to the $\mathrm{Na}(\mathrm{Hg})$ reduction of $\mathrm{Cp}_{3} \mathrm{UCl}\left(\mathrm{Cp}=\eta-\mathrm{C}_{5} \mathrm{H}_{5}\right)$. J. Electroanal. Chem. Interf. Electrochem. 1991, 313, 227-241.

26. Bard, A.J.; Faulkner, L.R. Electrochemical Methods - Fundamentals and Applications, Wiley: New York; 1980.

27. Klingler, R.J.; Kochi, J.K. Electron-transfer kinetics from cyclic voltammetry. Quantitative description of electrochemical reversibility. J. Phy. Chem. 1981, 85, 1731-1741. 
28. Wang, J. Analytical Electrochemistry, 3rd ed., John Wiley and Sons Inc.: New York; 2006; pp 29-39.

29. Greef, R.; Peat, R.; Peter, L.M.; Pletcher, D.; Robison, J. Instrumental Methods in Electrochemistry, John Wiley and Sons Inc.: New York; 1985.

30. Khan, A.S.A.; Ahmed, R.; Mirza, M.L. Kinetic and electrochemical studies of uranium in acetate and formate media by cyclic voltammetry. Radiochim. Acta 2007, 95, 693-699.

31. Khan, A.S.A.; Ahmed, R.; Mirza, M.L. Kinetics and electrochemical studies of uranium in perchlorate and sulphate media by cyclic voltammetry. J. Chem. Soc. Pak. 2008, 30, 170177.

32. Marcus, R.A. On the theory of electron-transfer reactions. VI. Unified treatment for homogeneous and electrode reactions. J. Chem. Phys. 1965, 43, 679-701. 